\title{
29061
}

\section{VULNERABILIDADE EM SEU ASPECTO ESTÁTICO E DINÂMICO: UMA ABORDAGEM DA BIOÉTICA COMPLEXA}

Aletheia Peters Bajotto, José Roberto Goldim

Unidade/Serviço: Bioética - HCPA

Introdução: Estudos demográficos apontam aumentos contundentes no tamanho da população idosa no mundo todo. Até o ano de 2025, o Brasil será o sexto país com o maior número de pessoas idosas no mundo. No ano de 2050 estima-se que tenhamos dois bilhões de pessoas idosas no mundo. Neste mesmo ano, os idosos no Brasil deverão chegar à incrível marca de 81,25 anos de idade, o que representa uma expectativa de vida alta. Sudeste e Sul, segundo os dados do Censo 2010, vêm se mantendo como as duas regiões mais envelhecidas do País. Em 2010 8,1\% da população era formada por idosos com 65 anos ou mais, enquanto a proporção de crianças menores de 5 anos era, respectivamente, de 6,5\% e 6,4\%. O bairro Moinhos de Vento, de Porto Alegre, Rio Grande do Sul, desbanca Copacabana, no Rio de Janeiro, como o Bairro das capitais brasileiras que tem maior proporção de idosos moradores. Dentre os 7.264 moradores, 2.487 são idosos. No campo da Bioética, a vulnerabilidade é um assunto vigente porque os indivíduos e grupos vulneráveis estão sujeitos à exploração - e a exploração é moralmente errada. É durante a velhice que se recordam e se expressam aspectos, como a vulnerabilidade e a temporalidade, que são típicos do ser humano e que passam despercebidos pela vitalidade que se experimenta na idade juvenil. A vulnerabilidade é um construto multidimensional que se refere a um contexto dinâmico em que há risco para o desenvolvimento de problemas de saúde, resultado de uma inadequação econômica, social, psicológica, familiar, cognitiva ou de recursos físicos. Objetivo: Geral: Verificar a caracterização da vulnerabilidade estática e dinâmica no contexto do envelhecimento, comparando grupos de idosos e não idosos em diferentes situações de atendimento em hospital-geral. Específicos: 1Descrever as características que tornam os indivíduos vulneráveis; 2 - Diferenciar a condição de "ser" e "estar" vulnerável, de acordo com as características descritas; 3 - Comparar qualidade de vida, capacidade de tomada de decisão, percepção de coerção na pesquisa, expressão de coerção na assistência e independência funcional nos diferentes grupos pesquisados; 4- Avaliar de forma qualitativa a percepção individual de grupo focais a respeito da vulnerabilidade. Método: A pesquisa caracteriza-se como transversal, quantitativa e quantitativa, avaliando 222 pacientes divididos em 6 diferentes grupos: 1 - idosos atendidos em ambulatório do HCPA, 2- Idosos internados no HCPA, 3- Idosos que participam de atividades no Celari/UFRGS, 4- Adultos atendidos em ambulatório, 5- Adultos internados no HCPA, 6- Adultos acompanhantes de pacientes internados no HCPA. Cada participante responde a cinco (5) questionários autoaplicáveis sendo estes: WHOQOL-BREF, Instrumento de Desenvolvimento Psicológico-Moral, Escala de percepção de Coerção na Pesquisa, Escala de Expressão de Coerção na Assistência e o Index de Katz. Dez (10) pacientes de cada grupo respondem a uma questão "O que significa para você, ser vulnerável"? Aspectos éticos: A coleta de dados iniciou no dia 20/03/13, após aprovação do Projeto pelo Comitê de Ética em Pesquisa do HCPA (130001). Os pesquisadores responsabilizam-se em resguardar a confidencialidade de dados de identificação pessoal que venham a constar no banco de dados da pesquisa. Todos os participantes serão convidados e participarão do processo de consentimento, que culmina com a assinatura do Termo de Consentimento Livre e Esclarecido (TCLE). Este documento foi elaborado de acordo com as Diretrizes e Normas Regulamentadoras de Pesquisas Envolvendo Seres Humanos (Resolução CNS 196/96), contando com linguagem clara e acessível. Serão apresentados dados preliminares e parciais do trabalho. 